\title{
Hyperbaric Oxygen in Trauma and Surgical Emergencies
}

\author{
C MacFarlane, FJ Cronje, CA Benn
}

Campbell MacFarlane,

Hons. BA, BSc (Hons),

MBChB, MMed

(Surg), PhD, FRCS

(Ed), FRCS (Eng),

FACS, FACEM (Hon.),

FFAEM, MRACMA,

DMCC

Gauteng Health

Department Emergency

Medical Services -

Johannesburg

Honorary Consultant,

Johannesburg Hospital

Trauma Unit -

University of

the Witwatersrand

E-mail:

macfarlaneca@ems.gpj.co.2a

Frans J Cronjé, BSc

(Hons) Aerosp Med,

$\mathrm{MBChB}$

Hyperbaric Unit,

Eugene Marais

Hospital, Pretoria

Carol-Ann Benn, MBBCh, FCS(SA), DIP.PEC(SA)

Consultant Surgeon,

Baragwanath Hospital,

Johannesburg,

University of the

Witwatersrand

\begin{abstract}
Hyperbaric oxygen therapy (HBO), that is the administration of $100 \%$ oxygen delivered under pressure, has a beneficial effect in several surgical conditions. Its use has been assessed and audited and its pharmacological effects demonstrated. It is appropriate for use in several acute surgical conditions as evidence-based therapy. These are:

- Gas Gangrene

- Crush Injuries, Compartment Syndromes \& Acute Traumatic Ischaemias

- Enhancement of Healing in Selected Problem Wounds

- Exceptional Bloodloss Anaemia

- Necrotising Soft Tissue Infections

- Compromised Skin Grafts \& Flaps

- Thermal Burns

HBO therapy suffers from previous inappropriate use, lack of knowledge, and scarce hyperbaric facilities. Hyperbaric therapy, when properly supervised by a physician trained in its use, working closely with a surgeon, and ethically used for appropriate indications, can be a useful adjunct to surgical practice. Military surgeons may be in a situation in which they can utilize HBO in acute surgical conditions and trauma. They are urged to identify $\mathrm{HBO}$ facilities, both fixed and portable, and to establish communication with hyperbaric therapy colleagues.
\end{abstract}

\section{Introduction}

Hyperbaric Oxygen therapy implies the administration of $100 \%$ oxygen breathed within an environment of increased pressure and delivered to the tissues, via the circulation, to achieve a therapeutic benefit. With the exception of arterial gas embolism, carbon monoxide poisoning and decompression sickness, where $\mathrm{HBO}$ is the definitive treatment, it is otherwise employed as an adjunctive therapy in surgical practice.

In spite of indiscriminate use in the past, hyperbaric oxygen therapy has now become more logical and evidence based when administered by ethical and experienced medical practitioners.
Military surgeons, some of whom have a background of diving medicine, are perhaps in a better situation to both understand and apply hyperbaric oxygen than some of their civilian colleages, since they may have access to formal hyperbaric facilities, but also may be able to utilise facilities primarily provided for the treatment of diving injuries. Even small, portable emergency chambers can be used for this purpose in emergency cases, providing there is understanding of the physiological and pathological processes involved and advice available from a hyperbaric physician in assessing the indications and for supervising therapy(1). This lends itself to a telemedicine linkup.

Many surgeons remain unaware of the potential benefits of hyperbaric oxygen therapy. As far as military surgery is concerned, if war injuries are being received into base hospitals for example, $\mathrm{HBO}$ has been shown to be of value in cases of successful vascular repair with persistent signs of peripheral ischaemia(2). HBO has an established place in several acute surgical conditions particularly trauma. In the United States a significant number of trauma centres have hyperbaric chambers in close association (eg. Shock Trauma, Baltimore).

\section{Mode of Action}

HBO provides a pressure-related increase in plasma-borne oxygen. This increases total blood oxygen content by $20-25 \%$ (3) and markedly improves free (i.e. dissolved) oxygen delivery to tissues, increasing the diffusion distance from the capillaries into tissues several fold(4). At these increased tissue levels, oxygen initiates a series of distinct physiological and pharmacological effects.

The therapeutic range for oxygen therapy is an inspired oxygen partial pressure (piO2) of 1.5 to 3 times atmospheric pressure (ATA). Higher oxygen pressures (>3 ATA) are too toxic for clinical use. There are five groups of therapeutic mechanisms attributed to hyperbaric oxygen use: -

- Hyperoxygenation

- Vasoconstriction

- Neovascularisation (Angiogenesis)

- Altered Cellular Function

- Pressure and Gas Gradients 


\section{Hyperoxygenation}

Even under normal air-breathing conditions, haemoglobin is almost fully saturated with oxygen, but, a small, biologically active amount of dissolved oxygen in the plasma increases significantly and proportionally to an increasing inspired oxygen pressure. Under standard treatment pressure (2.5 ATA) the delivery of dissolved oxygen to body tissues is increased from $0.3 \mathrm{ml} 0_{2}$ per $100 \mathrm{ml}$ of blood to $5.5 \mathrm{ml} \mathrm{O}_{2}$ per $100 \mathrm{ml}$ blood - enough to sustain life temporarily even without haemoglobin(5). Arterial blood gas values exceed 2000 mmHg (263 $\mathrm{kPa}) \quad \mathrm{paO}_{2}$ under these conditions(6). HBO therefore not only adds a greater amount of "free" oxygen to the blood, but also establishes a steep diffusion gradient from the capillaries, driving the oxygen further into the tissues(7). It is to be emphasized that this oxygen must be carried by the circulation from the lungs to the tissues(8). Hyperbaric oxygen therapy does not presume absorption of oxygen through the skin.

\section{Vasoconstriction}

HBO causes pre-capillary vasoconstriction in non-ischaemic tissues, leaving the capillaries in ischaemic areas unaffected(9). This results in reduced hydrostatic pressure in the capillaries, with less fluid extravasation, while hyper-oxygenation continues. In the venules, interstitial fluid is absorbed, the end result being a rapid and significant reduction in oedema(10). This has important implications, particularly in trauma and burns.

\section{Neovascularisation (Angiogenesis)}

A steep oxygen gradient between normal and abnormal tissues is a fundamental stimulus to angiogenesis(11). In some abnormal tissues (irradiated, diabetes, etc.), the gradient is so shallow that there is little stimulus breathing air of even $100 \%$ oxygen at 1 ATA. HBO however, accentuates the oxygen gradient sufficiently to stimulate angiogenesis in these tissues $(11,12)$. As a result, neovascularisation (granulation tissue formation) is enhanced in these abnormal tissues while normal tissues are unaffected. The microvascular revascularisation is long-lasting and affords durable results(12).

\section{Altered Cell Function}

$\mathrm{HBO}$ affects the cells involved in healing. Normal tissue oxygen levels are necessary for healing to occur. HBO therapy, even once a day, has been shown to significantly improve healing in chronic ulcers(13). The intermittent periods of hyperoxia result in extended periods of normal cell function. Periods of tissue hypoxia between treatments encourage the production of cytokines(14), which stimulate healing, while cellular response to cytokines is again oxygen dependent(15). This conflicting need for both hypoxia and normal oxygen saturation is called the "oxygen paradox".

Leukocyte defense mechanisms are largely oxygen dependent(16). Anaerobic phagocytosis can occur, but large amounts of oxygen are necessary for bactericidal activity(17). Work by Knighton and Hunt has demonstrated that even breathing $45 \%$ oxygen is as effective as ampicillin incontrolling certain aerobic bacterial inoculations, by stimulating leukocyte function(18). In addition $\mathrm{HBO}$ also enhances the efficacy of certain antibiotics (e.g. penicillins, aminoglycocides, vancomycin, and clindamycin) without increasing their toxicity(19).

Fibroblasts cannot produce collagen anaerobically and the tensile strength of collagen (crosslinking) is also oxygen dependent(20). Leukocyte adherence to venules is an important pathophysiological mechanism in ischaemic reperfusion complications that leads to the no-reflow phenomenon. HBO inhibits leukocyte endothelial adherence for a period of 12 hours after one treatment without impairing leukocyte response to infection(21).

In the case of fractures, tissue hypoxia may result in cartilage formation instead of bone, predisposing to delayed or nonunion(22). HBO, if applied early, appears to preferentially stimulate bone formation(23).

\section{Pressure and Gas Gradients}

In arterial gas embolism or decompression sickness, seen in divers, an increase in ambient pressure can reduce the diameter of inert gas bubbles, lessening their obstructive effects(24). By breathing oxygen at pressure, the steep gas gradients promote inert gas elimination, ischaemic or hypoxic complications are reduced and cerebral or spinal oedema is reduced by selective vasoconstriction(25).

\section{Provision of $\mathrm{HBO}$}

HBO therapy is provided by hyperbaric chambers. These pressure vessels may be multiperson, being pressurised by air. Patients breathe oxygen by means of a mask or head tent in the chamber. This allows patients to have "air breaks" during treatment, breathing chamber air for short periods, thus avoiding cumulative oxygen toxicity.

Single person chambers are small, transparent tubes that are pressurized with oxygen. This avoids the complex oxygen delivery systems required in multiplace chambers. However, by using pure oxygen inside the chamber, there is a greater risk of fire and stringent precautionary measures must be adhered to. Air breaks are provided by a demand valve and oro-nasal mask. 
Although no physical patient contact is possible during therapy, invasive and non invasive monitoring, intravenous infusion, drug administration and even ventilation can safely and effectively be performed with these systems.

The use of oxygen under pressure has been likened to it acting as a drug, with implicit factors such as indications, dose, length of use, effectiveness, contra indications and complications(26).

Many hyperbaric therapists follow the recommendations of the United States based Undersea and Hyperbaric Medical Society (UHMS) with regard to appropriate and ethical indications for $\mathrm{HBO}$ administration. UHMS is an international peer review and scientific authority of more than 2,500 scientists and clinicians which standardises therapy and validates indications with the most up to date literature. UHMS recognizes 13 evidence based indications for $\mathrm{HBO}$ at the present time (27) These are: -

- Arterial Gas Embolism

- Carbon Monoxide Poisoning

- Gas Gangrene

- Crush Injuries, Compartment Syndromes and Acute Traumatic Ischaemia

- Decompression Sickness

- Enhancement of healing in selected wound problems

- Exceptional Blood Loss Anaemia

- Necrotising Soft Tissue Infections

- Refractory Osteomyelitis

- Radionecrosis

- Compromised Skin Grafts and Flaps

- Thermal Burns

- Intra Cranial Abscess

\section{Surgical Indications}

The surgical indications, as can be seen from the above list, are considerable. Acute surgical and trauma conditions suitable for consideration for $\mathrm{HBO}$ therapy are discussed below. HBO is often not considered or even thought about in the management of such cases through a combination of lack of knowledge or lack of HBO facilities.

\section{Gas Gangrene}

This is the classic indication for hyperbaric oxygen in combination with conservative surgery and antibiotics. When used early (i.e. within 24 hours of diagnosis), and before ablative surgery, HBO reduces morbidity and mortality significantly(28). Tissue and limbs can often be spared and spread to the trunk, which carries a high mortality, can be avoided. HBO terminates the production of alpha toxin, the lethal element of gas gangrene, within minutes and prevents ongoing liquefaction of tissue(29). The need for extensive debridement or amputation is thereby significantly reduced. Following HBO, along with resuscitation and antibiotics, patients are in a better state for surgery and, important for the surgeon, the demarcation between viable and non-viable tissue is more distinct, thereby avoiding overexcision of tissue in the initial stages(28, 29).

\section{Crush Injuries and Active Ischaemia}

Crush injuries, compartment syndromes, thermal burns, compromised flaps and tissue replantations share a number of pathophysiological processes that benefit from adjunctive HBO. In all these injuries a gradient of injury exists, ranging from viable to non-viable tissue. Secondary pathophysiological events, e.g. hypoxia, ischaemia, oedema, reperfusion injury and sepsis, shift the gradient towards further tissue loss. Hyperbaric oxygen, if introduced early, improves outcome, by reducing the effects of ischaemia and hypoxia and reducing oedema and necrosis as confirmed clinically in a recent prospective, randomised, double blinded and placebo controlled trial by Bouachour et al (30). Here HBO was able to limit the number of repetitive surgical procedures in relation to severe limb trauma.

\section{Selected Wound Care}

In infected diabetic foot wounds and gangrene, $\mathrm{HBO}$ has been shown to be effective by a number of authors $(31,32,33$, 34, 35). Patients with Wagner grades III (deep infection) and IV (fore-foot gangrene) foot infections derive significant benefits from $\mathrm{HBO}$ (with appropriate vascular interventions when indicated): Oriani et al confirmed a significant reduction in below-knee amputation rates in $\mathrm{HBO}$ treated patients (5\% vs $33 \%$ ) compared to matched controls(31). Similarly Cianci et al achieved 85\% long term (average 54 months) limb salvage rates(32). For $\mathrm{HBO}$ to be of value, transcutaneous oximetry values should confirm adequate oxygen delivery to the affected areas $(450 \mathrm{~mm} \mathrm{Hg} \mathrm{pO} 2$ at 2.5 ATA) $(35,36)$. For best results, HBO should be combined early in the management of these patients.

\section{Exceptional Blood Loss Anaemia}

In exceptional blood loss anaemia or certain situations where transfusion in not possible (e.g. Jehovah's Witnesses), the intermittent use of $\mathrm{HBO}$ dissolves enough oxygen in the plasma to support basic metabolic needs(5). This can be continued together with aggressive erythropoietin therapy until the body has produced sufficient red blood cells(27).

\section{Necrotising Soft Tissue Infections}

As an adjunct to surgical debridement and systemic antibiotics, HBO directly inhibits 
anaerobic bacterial growth and indirectly improves the body's response to aerobic infections by potentiating white cell bacterial killing(37). The principle treatment remains surgical debridement and antibiotics, but $\mathrm{HBO}$ is of use in high risk (e.g. perineal and truncal infections) or poorly responding patients. Riseman and Zamboni obtained a mortality reduction from $66 \%$ to $23 \%$ in such cases, with considerably less debridement required(38). Hollabaugh, in a recent study on Fournier's gangrene, demonstrated a nine fold reduction in mortality in matched, randomised patients(39). If the progression of the disease is not arrested with adequate surgery and antibiotics within 48-hours, patients should be referred for $\mathrm{HBO}$ if possible.

\section{Compromised Skin Grafts, Flaps and Reimplantations}

Early application of $\mathrm{HBO}$ is associated with improved tissue salvage in compromised flaps(40). HBO can improve flap survival and extend the margins of viable tissue while reducing the risk of sepsis $(15,16,17)$. While revision of vascular anastomoses is required for inflow obstruction, $\mathrm{HBO}$ is able to attenuate the ischaemia reperfusion process that would follow reflow. Flap mottling after surgery is therefore an important emergency indication for $\mathrm{HBO}(41)$. Similarly, in limb or tissue loss followed by re-implantation, $\mathrm{HBO}$ attenuates ischaemia-reperfusion, supports the avulsed or degloved tissue after reattachment, and stimulates angiogenesis and healing(42).

\section{Thermal Burns}

$\mathrm{HBO}$ in burns has the ability to maintain microvascular integrity, reduce local and systemic oedema and minimise propagation of the burn into adjacent and subjacent tissues(43). Mortality, hospital stay and graft requirements are positively affected $(44,45)$. Epithelialisation is also promoted, thereby reducing the incidence of contractures as a time-course related complication(45). HBO may prevent partial thickness burns from becoming full thickness if applied early(46).

$\mathrm{HBO}$ is not a substitute for established burn care but is a useful adjunct if applied early. Thirty one per cent of burn units in the USA routinely use $\mathrm{HBO}$ as part of their treatment regimens. Standard resuscitation and burn care must be continued in the hyperbaric environment(47).

\section{Dangers, Side Effects and Special Precautions}

The most common problem is barotrauma of the middle ear. Patients are taught autoinflation techniques and sometimes decongestants are used. If necessary, grommets can be inserted. In emergency treatments in unconscious patients, myringotomy is performed.

Prolonged exposure to high-pressure oxygen can cause two potentially serious side-effects: seizures and pulmonary oxygen toxicity. Both of these are very rare, as safe therapeutic limits have been developed over time. Oxygen toxicity seizures are not inherently harmful, and air breathing intervals during $\mathrm{HBO}$ therapy are factored into treatment regimens and prophylactic vitamin $\mathrm{E}$ is administered to further minimize the risk(48). Careful history is taken and prophylactic treatment is given in those with specific risk factors; e.g. those with history of seizures, fever, acidosis, or low blood sugar.

Claustrophobia may be a problem with some patients, and it is reduced by having an attendant inside the chamber (multiplace) or beside it (monoplace). Mild sedatives are sometimes indicated.

Fire risk precautions are mandatory, with unsafe objects not being admitted. Patients are expected to stop smoking for the entire course of HBO therapy. The vasoconstrictive effects of nicotine may interfere with angiogenesis, and raised carbon monoxide levels reduce the full benefit of oxygenation.

\section{Contra-Indications to HBO}

The only absolute contra-indications are an untreated pneumothorax and certain anticancer drugs, i.e. doxorubicin, bleomycin and cis-platinum, as $\mathrm{HBO}$ significantly increases their cytotoxicity.

Relative contra-indications include acute viral URTI's, sinusitis, bullous pulmonary disease, history of spontaneous pneumothorax and congenital spherocytosis. Consultation with a physician trained in hyperbaric medicine is important, both for evaluating the indication for HBO therapy and for addressing any possible contraindications.

\section{Conclusion}

HBO therapy suffers from a legacy of unqualified, non-evidence based use in the past, compounded by a lack of knowledge and teaching on the subject and paucity of hyperbaric facilities. The past decade has seen a dramatic increase in the understanding of the pharmacological effects of oxygen administered in hyperbaric dosages.

In acute surgical disorders, $\mathrm{HBO}$ reduces morbidity and mortality. Treatments are few in number (7-12) with obvious and significant benefits: fewer complications, fewer new surgical procedures, better functional outcomes and reduced hospital stay.

HBO therapy, when applied ethically, 
properly and safely by a qualified hyperbaric physician, is a powerful and valuable adjunct, and surgeons should be aware of its capability and potential to assist them in their practice.

Military surgeons may be in a situation in which they can utilize this useful adjunct to surgical practice in acute surgical and trauma conditions. They are urged to identify appropriate facilities, fixed or portable, utilizing them when appropriate, in conjunction with hyperbaric therapy colleagues.

\section{References}

1. Personal Experience. British Military Hospital, Singapore-1971.

2. Shramek A, Hashmonai M. Vascular injuries in the extremities in battle casualties. $\mathrm{Br} f \mathrm{Surg}$ 1977;44:644-648

3. Walen $\mathrm{R}$, Salzman $\mathrm{H}$, Holloway $\mathrm{D}$ et al. Cardiovascular and blood gas responses to hyperbaric oxygenation. $A m \quad \mathcal{f}$ Cardiol 1965;15:638-46.

4. Krogh A. The number and distribution of capillaries in muscle with calculations of the oxygen pressure head necessary for supplying the tissue. F Physiol 1919;52:409-415.

5. Boerema I, Meijne NG, Brummelkamp WH, et al. Life without blood. A study of the influence of high atmospheric pressure and hypothermia on dilution of blood. F Cardiovasc Surg 1960;1:133146.

6. Hunt TK, Twomey $\mathrm{P}$, Zederfeldt $\mathrm{B}$, et al. Respiratory gas tension and $\mathrm{pH}$ in healing wounds. Am F Surg 1967;114:302-308.

7. Sheffield PJ. Tissue oxygen measurement. In Davis JC, Hunt TK (eds.). Problem wounds, the role of oxygen. 1988. P 17-51. Elsevier, New York.

8. Weiss LD, Van Meter KW. The applications of hyperbaric oxygen therapy in emergency medicine. American fournal of Emergency Medicine 1992;10(6):558-568.

9. Zamboni WA, Roth AC, Russel RC, Graham B, Suchy H, Kucan JO. Morphological analysis of the microcirculation during reperfusion of ischemic skeletal muscle and the effect of hyperbaric oxygen. Plast Reconstr Surg 1993;91:1110-23.

10. Nylander G, Lewis D, Nordstrom H, Larsson NJ. Reducion of post-ischemic edema with hyperbaric oxygen. Plast Reconstr Surg 1985;77:596-603.

11. Ketshum SA III. Thomas AN, Hall AD. Angiographic studies of the effects of hyperbaric oxygen on burn wound revascularization, in Wada $\mathrm{J}$, Iwa $\mathrm{T}$ (eds.). Proceedings of the Fourth International Congress in Hyperbaric Medicine. Baltimore, Williams and Wilkins, 1969,pp 388394.

12. Marx RE. A new concept in treatment of osteoradionecrosis. Journal of Oral Maxillofacial Surgery 1983;41:351-357.

13. Hammarlund C, Sundberg T. Hyperbaric oxygen reduced size of chronic leg ulcers. A randomized double-blind study. Plastic and Reconstructive Surgery 1994;93(4):829-834

14. Knighton DR, Oredsson S, Banda $\mathrm{M}$, et al. Regulation of repair: Hypoxic control of macrophage mediated angiogenesis, in Hunt TK, Heppenstall RB, Pines E, et al (eds.). Soft and Hard Tissue Repair. New York: Praeger, 1984, pp 41-49.

15. Hunt TK et al. (1978). Anaerobic metabolism and wound healing-an hypothesis for the initiation and cessation of collagen synthesis in wounds. $A m \mathcal{F}$ Surg 135:328-332.

16. Niniikoski J, Hunt TK. Oxygen and healing wounds: tissue-bone repair enhancement. Handbook on Hyperbaric Medicine 1996:485-507.
17. Rabkin JM, Hunt TK (1988). Infection and oxygen, In: Davis JC, Hunt TK (eds.). Problem wounds, the role of oxygen. Elsevier, New York 116

18. Knighton DR, Halliday B, Hunt TK. Oxygen as an antibiotic: A comparison of the effects of inspired oxygen concentration and antibiotic administration on in vivo bacterial clearance. Arch Surg 1986;121:191-195.

19. Marzella L, Vexxani G. Effect of hyperbaric oxygen on activity of antibacterial agents. Oriani G, Marroni A, Wattel F (Eds.). Handbook of Hyperbaric Medicine; 1996; Springer, London; ISBN 3-540-75016-9.

20. Hunt TK, Pai MP. The effect of varying ambient oxygen tensions on wound metabolism and collagen synthesis. Surg Gyecol Obstet 1972;135:561-567.

21. Thom SR, Mendiguren I, Hardy K, Bolotin T, Fisher D, Nebolon M, Kilpatrick L. Inhibition of human neutrophil beta2-integrin-dependent adherence by hyperbaric O2. Am $\mathcal{f}$ Physiol 1997;273:C770-7.

22. Mally R, Kolodny S. Osteogenesis enhancement. In: Hyperbaric oxygen therapy. Davis JC, Hunt TK eds., 1977. Undersea Medical Society, Bethesda MD, pp 281-285.

23. Basset CAL, Hertzman I. Influence of oxygen concentration and mechanical factors on diferentiation of connective tissue in vitro. Nature; 1967:190:460-461.

24. Moon RE. Treatment of gas bubble disease. Problems in Respiratory Care 1991;4(2):232-252.

25. Sukoff $M H$., Ragatz RE. Hyperbaric oxygen for the treatment of acute cerebral edema. Neurosurgery 1982;10:29-38.

26. Hunt TK, Niinikoski J, Zederfeldt BH. Oxygen in wound healing enhancement: cellular effects of oxygen. In: Hyperbaric oxygen therapy. Davis JC, Hunt TK eds., 1977. Undersea Medical Society, Bethesda MD, pp 111-122.

27. Hyperbaric Oxygen Therapy Committee Report, Hampson NH, ED; 1999; Undersea and Hyperbaric Medical Society, Bethesda, Maryland.

28. Hart GB, Strauss MB. Gas gangrene-clostridial myonecrosis: a review. Fournal of Hyperbaric Medicine 1990;5(2):125-144.

29. Bakker DJ. Clostridial myonecrosis. In: Problem Wounds, The Role of Oxygen, Eds. Davis JC and Hunt TK 1988:153-172. Elsevier publishing Company, New York.

30. Bouachour G, Cronier P, Gouello JP, Toulemonde JL, Talha A, Alquier P. Hyperbarix oxygen therapy in the management of crush injuries: a randomized double-blind placebo controlled clinical trial. $\mathcal{f}$ Trauma 1996;41:333-9.

31. Oriani G, Meazza D, Favales F, et al. Hyperbaric oxygen therapy in diabetic gangrene. Fournal of Hyperbaric Medicine 1990;5(3):171-175

32. Cianci P, Petrone G, Drager S, et al. Salvage of the problem wound and potential amputation with wound care and adjunctive hyperbaric oxygen therapy: an economic analysis. Fournal of Hyperbaric Medicine 1988;3(3):127-141.

33. Doctor N, Pandya S, Supe A. Hyperbaric oxygen therapy in diabetic foot. Fournal Postgrad Medicine 1992;38(3):112-114.

34. Faglia E, Favales F, Aldeghi A, Calia $P$ Quarantiello A, Oriani G, Michael M, Campagnoli P, Morabito A. Adjunctive systemic hyperbaric oxygen therapy in the treatment of severe prevalently ischemic diabetic foot ulcer. A randomised study. Diabetes Care 11996;19:133843

35. Mathieu D, Wattel F et al. (1990). Hyperbaric oxygen in the treatment of the diabetic foot. Undersea Biomed Res 17 (Suppl): 160-161.

36. Mathieu D, Wattel F et al. (1991). Hyperbaric oxygen in the treatment of diabetic foot lesions. $\mathcal{F}$ Hyperb Med 6:263-268.

37. Knighton DR, Halliday B, Hunt TK. Oxygen as an antibiotic: A comparison of the effects of 
inspired oxygen concentration and antibiotic administration on in vivo bacterial clearance. Arch Surg 1986; 121:191-195.

38. Riseman JA, Zamboni WA, Curtis A, et al. Hyperbaric oxygen therapy for necrotizing fasciitis reduces mortality and the need for debridements. Surgery 1990:108:847-850.

39. Holabaugh RS: Jr, Fournier's Gangrene. Therapeutic Impact of Hyperbaric Oxygen. $C E$ Plast Reconstr Surg 1998. Jan;101(1):94-100.

40. Zamboni WA, Roth AC, Russel RC, et al. The effect of acute hyperbaric oxygen therapy on axial pattern skin flap survival when administered during and after total ischemia. Fournal of Reconstructive Microsurgery 1989;5(4):34-345.

41. Zamboni WA, Roth AC, Russel RC, et al. Morphologic analysis of the microcirculation during reperfusion of ischemic skeletal muscle and the effect of hyperbaric oxygen. Plastic and Reconstructive Surgery 1993;89(5):916-923.

42. Zamboni WA. Applications of hyperbaric oxygen therapy in plastic surgery. Oriani G, Marroni A, Wattel F (Eds). Handbook of Hyperbaric Medicine; 1996;443-483. Springer, London: ISBN 3-54075016-9.

43. Nizgoda JA. The effect of hyperbaric oxygen therapy on a burn wound model in human volunteers. Plast Reconstr Surg 1997 May;99(6):1620-162. Double Blind. Prospective Randomised.

44. Cianci P, Lueders HW, Lee HW, Lee H, et al. Hyperbaric oxygen therapy reduces length of hospitalization in thermal burns. Fournal of Burn Care and Rehabilitation 1989;10:432-435.

45. Cianci P, Williams C, Lueders $\mathrm{H}$, et al. Adjunctive hyperbaric oxygen in the treatment of thermal burns: an economic analysis. The fournal of Burn Care E Rehabilitation 1990;11(2):140-143.

46. Germonpre P, Reper P, Vanderkelen A. Hyperbaric oxygen therapy and piracetam decrease the early extension of deep partialthickness. Burns 1996;22(6):468 - 473.

47. Cianci P, Sato R. Adjunctive hyperbaric oxygen therapy in the treatment of thermal burns: a review. Burns 1994;20(1):5-14.

48. Hart GB, Strauss MB. Central nervous system oxygen toxicity in a clinical setting. In: Bove AA, Bachrach AJ, Greenbaum LJ, eds: Undersea and hyperbaric physiiology IX. Proceedings of the ninth international symposium on underwater and hyperbaric physiology. Bethesda, MD. Undersea and Hyperbaric Medical Society . 1987:695-699. 